\title{
Theo Kölzer (éd.), Die Urkunden Ludwigs des Frommen
}

\section{Warren Pezé}

\section{OpenEdition \\ Journals}

Édition électronique

URL : http://journals.openedition.org/ifha/8679

DOI : $10.4000 /$ ifha. 8679

ISSN : 2198-8943

Éditeur

IFRA - Institut franco-allemand (sciences historiques et sociales)

\section{Référence électronique}

Warren Pezé, «Theo Kölzer (éd.), Die Urkunden Ludwigs des Frommen», Revue de l'IFHA [En ligne], Date de recension, mis en ligne le 01 février 2017, consulté le 24 septembre 2020. URL : http:// journals.openedition.org/ifha/8679; DOI : https://doi.org/10.4000/ifha.8679

Ce document a été généré automatiquement le 24 septembre 2020.

(CIFHA 


\section{Theo Kölzer (éd.), Die Urkunden Ludwigs des Frommen}

Warren Pezé

\section{RÉFÉRENCE}

Theo Kölzer (éd.), Die Urkunden Ludwigs des Frommen, Wiesbaden: Harrassowitz Verlag, 2016, LXXXVIII+VI+VI+1676 p., 3 volumes, $310 €$ 
Opportunément publiés pour le $1200^{\mathrm{e}}$ anniversaire du couronnement impérial de Reims, les trois volumes du recueil des actes de Louis le Pieux (814-840) apportent la dernière pierre à l'édition des diplômes des Carolingiens par les Monumenta Germaniae historica commencée en 1906 avec le volume consacré à Pépin, Carloman et Charlemagne. La présente édition, entreprise dès la fin des années 1900 par Ernst Müller, fut retardée aussi bien par les accidents de l'histoire du $\mathrm{XX}^{\mathrm{e}}$ siècle que par les changements de trajectoire scientifique des éditeurs successifs (voir la préface, p. IX-XV). Les historiens ayant pris l'habitude de citer les actes de Louis le Pieux d'après les Regesta imperii de Johann Friedrich Böhmer et de Engelbert Mühlbacher

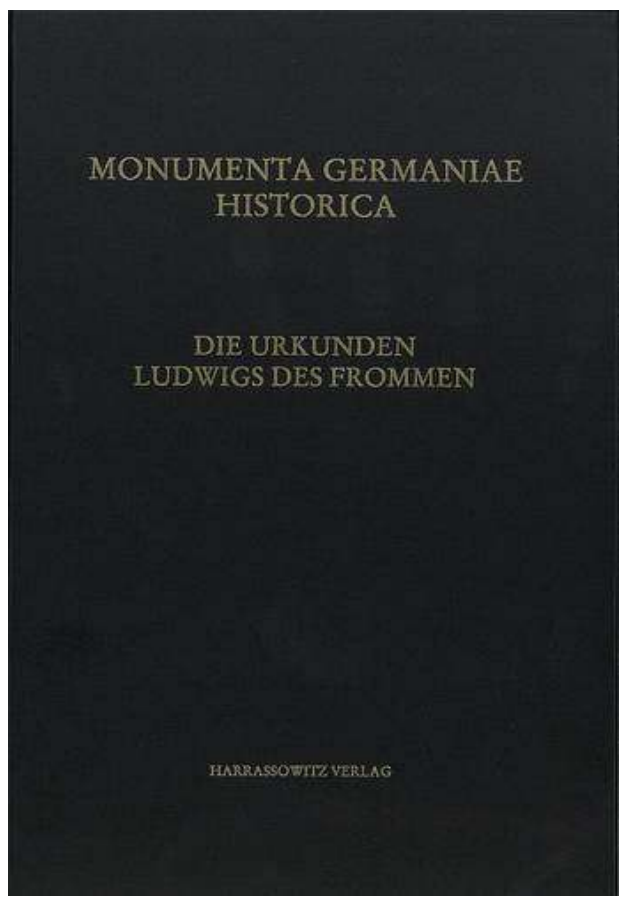
(seconde édition, 1908), la table des correspondances (vol.3, p. 1641-1660) se révèle indispensable. L'édition embrasse 418 actes (dont 92 originaux), auxquels s'ajoutent 6 falsifications modernes, 231 deperdita (actes perdus mais évoqués par d'autres sources), les 52 formulae imperiales du manuscrit Paris, BNF, latin 2718 et, sous forme de regesta, 21 lettres de Louis (dont la $\mathrm{n}^{\circ} 4$, adressée à Agobard de Lyon sur la réforme canoniale, restée inédite jusqu'à présent).

Le corpus en lui-même n'ajoute pas grand-chose à l'inventaire de Mühlbacher : seuls deux diplômes ( $n^{\circ} 6$ et 342$)$ lui avaient échappé, un autre $\left(n^{\circ} 126\right)$ était resté inédit. Le premier apport majeur du travail d'édition mené par Theo Kölzer (qui a réédité les actes mérovingiens aux MGH en deux volumes en 2001, d'où de fructueuses comparaisons) réside d'abord dans le discrimen veri et falsi (p. XXI). 91 actes sont considérés comme des falsifications (43 de plus que dans les Regesta imperii). Un point retiendra l'attention des historiens : la typologie des diplômes distingue plusieurs niveaux d'authenticité. Aux manuscrits falsifiés (unecht) s'ajoutent les manuscrits interpolés (interpolierte), dans lesquels le texte a été modifié de telle sorte que son intention significative a elle aussi été modifiée, et les manuscrits dénaturés (verunechte), dans lesquels la modification du texte ne change pas l'intention significative (p. XXI-XXII). La proportion d'actes manipulés d'une façon ou d'une autre s'élève ainsi à $34,6 \%$, proportion comparable à celle des actes de Charlemagne et bien supérieure à celle des successeurs de Louis.

Les éditeurs ont fait le choix de la prudence en ce qui concerne la description de la chancellerie au regard des actes préservés : l'introduction apporte ici une importante contribution aux débats entourant la chancellerie carolingienne (p. XXVI-XLIII). Suivant Theodor Schieffer et Georges Tessier, les éditeurs s'inscrivent en faux contre les méthodes - celles, en particulier, d'Otto Dickau - qui prétendent reconstituer le milieu des notaires par comparaison du texte des actes et de leur écriture (jusqu'à la couleur de l'encre). Dans le cas des textes (notamment l'arenga), les notaires ne suivent 
pas à la lettre un hypothétique formulaire mais «jonglent avec leurs modèles » en faisant preuve d'une certaine liberté de composition (p. XXVI). Quant à l'écriture, la comparaison des 92 originaux a permis de distinguer 52 documents dont les scribes ont composé au moins deux actes, de 40 documents dont la plume n'apparaît qu'une fois un nombre qui dépasse largement la petite équipe de notaires que l'on imaginait. Cet important résultat remet en cause l'image bureaucratique et hiérarchique de la chancellerie élaborée par Theodor Sickel au XIX ${ }^{\mathrm{e}}$ siècle.

L'édition des actes de Louis apportera beaucoup à l'histoire politique de l'empire carolingien. Avec une moyenne annuelle (p. XXIV) de 12,5 actes (authentiques) par an (16,2 si l'on inclut ses fils, contre 3,6 sous Charlemagne), Louis se hisse à un niveau qui ne fut dépassé que sous Charles le Gros $(17,45) .40$ \% des diplômes sont datés de 814-820, une concentration dans les premières années de règne que l'on constate chez tous les Carolingiens (p. XXIII). Certaines années sont particulièrement sinistrées : 824 (avec la campagne de Bretagne), 827 (l'année des périls aux frontières orientale et occidentale) et 830 (avec la première révolte). L'analyse du sceau royal montre que les notaires ne possédaient qu'un seul type $\left(\mathrm{S}_{1}\right)$, qui fut détruit après la déposition de Louis en 833 , si bien qu'il fallut en confectionner un second en $834\left(\mathrm{~S}_{2}\right) .93 \%$ des diplômes sont destinés à des clercs et à des institutions ecclésiastiques, 28 institutions se taillant la part du lion avec $47,3 \%$ de l'ensemble des actes (citons les chefs de file, p. XXV : Saint-Denis, Aniane, Farfa, Le Mans, Prüm, Kempten, Corvey, Fulda, Saint-Martin). Ce monopole clérical s'explique en grande partie par les discontinuités de la conservation des archives laïques. Les formulae imperiales, dont la moitié a pour destinataires des laïcs, reflète mieux la diversité réelle des activités de la chancellerie. On le voit, les 1676 pages de cette édition tant attendue apporteront à l'historien un instrument de travail dont il faut louer, en même temps que l'impeccable rigueur, la grande prudence.

\section{INDEX}

Index chronologique : Moyen Âge

Thèmes : Histoire des États et des pouvoirs, Histoire du droit, Sources

\section{AUTEURS \\ WARREN PEZÉ}

Tübingen, SFB 923 « Bedrohte Ordnungen » 